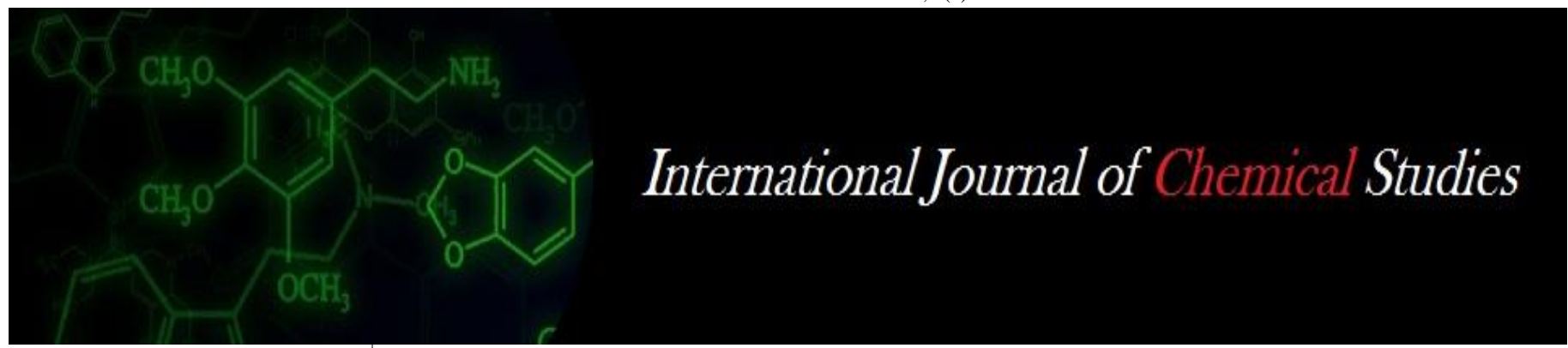

P-ISSN: 2349-8528

E-ISSN: 2321-4902

www.chemijournal.com

IJCS 2021; 9(1): 666-668

(C) 2021 IJCS

Received: 22-10-2020

Accepted: 26-12-2020

Sonali RA Soyam

Department of Horticulture,

Post Graduate Institute,

Mahatma Phule Krishi

Vidyapeeth, Rahuri,

Maharashtra, India
Corresponding Author: Sonali RA Soyam Department of Horticulture, Post Graduate Institute, Mahatma Phule Krishi Vidyapeeth, Rahuri, Maharashtra, India

\section{Effect of gamma rays on chlorophyll content and ascorbic acid content of chilli in $M_{1}$ generation}

\section{Sonali RA Soyam}

DOI: https://doi.org/10.22271/chemi.2021.v9.i1i.11305

\begin{abstract}
This study was performed by exposing the seeds of chilli (Capsicum annuum L.) cv. Phule Jyoti to gamma rays. The observations were made on chlorophyll content and Ascorbic acid content of chilli. The study revealed that ascorbic acid content decreased with an increase in dose/concentration of gamma rays as compared to control. Whereas in Chlorophyll content, maximum chlorophyll ' $a$ ' was observed in control, chlorophyll ' $b$ ' in lower dose of radiation and total chlorophyll in higher dose of gamma rays. Higher dose of radiation showed minimum chlorophyll ' $a$ ' and ' $b$ ' in $\mathrm{M}_{1}$ generation.
\end{abstract}

Keywords: Gamma rays, chlorophyll, ascorbic acid, chilli

\section{Introduction}

Chilli is a spice cum vegetable crop of commercial importance, characterized by tempting colour and biting pungency. No dish will fulfill without this spice in India. India is blessed with a plethora of chilli varieties which are as fresh green fruits, fresh red fruits, and dried red fruits or processed in to chilli paste, chilli powder, oleoresin etc. It is grown in several parts of India has a larger area; its productivity is very low as compared to other countries. Hence, there is an urgent need to produce and identify new varieties combining with high level of disease resistance, besides increased yield and capsaicin content in chilli.

Mutation is a sudden heritable change, brought out in a single nucleotide base pair either by addition, deletion or substitution caused by the various factors which leads to a change in the coded information finally expressed in terms of changed phenotypes through alteration in the chain of events like transcription and translation. Gamma rays are ionizing physical mutagens, capable of inducing mutation in plants and animals. Gamma rays are electromagnetic radiations, similar to X-rays in their physical characteristics and have an action on the organism. They are of very short wavelength by virtue of which they are more penetrating.

\section{Material and Methods}

The present investigation was carried out at All India Co-ordinated Research Project on Vegetable crops, Department of Horticulture, Mahatma Phule Krishi Vidyapeeth, Rahuri during 2014-2015. The selected seeds of Chilli cv. Phule jyoti (15 g for each treatment) were treated with different doses of gamma rays viz. 10, 20, $30 \& 40 \mathrm{kR}$ at Bhabha Atomic Research Centre, Trombay, Mumbai.

\section{Chlorophyll content (mg/g)}

The chlorophyll content in leaf was estimated by adopting the procedure and extraction of chlorophyll was done with DMSO (Dimethyl Sulphoxide) method. The leaf samples weighing $0.100 \mathrm{~g}$ were added in test tubes containing $10 \mathrm{ml}$ DMSO solution and kept in BOD incubator for 2 hours at $60{ }^{\circ} \mathrm{C}$ for extraction of chlorophyll. The supernatant was used for estimation of pigments. The optical density of the aliquot was measured on spectrophotometer at the wavelength of $663 \mathrm{~nm}$ for chlorophyll a, $645 \mathrm{~nm}$ for chlorophyll b and $652 \mathrm{~nm}$ for total chlorophyll with red filter. 
The chlorophyll prom leaves calculated as per Arnon (1949) equations and was expressed in mg/g.

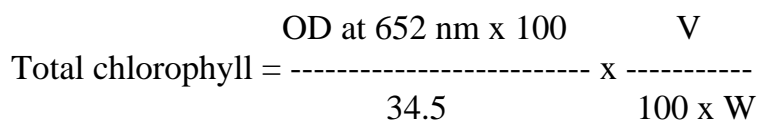

Where

$\mathrm{OD}=$ Optical density

$\mathrm{V}=$ Final volume i.e. $10 \mathrm{ml}$ of DMSO.

$\mathrm{W}=$ Weight of fresh leaves $(\mathrm{g})$

Chlorophyll a = 12.7 (OD at 663) - 2.69 (OD at 663) - 2.69 (OD at 645) x $-\frac{V}{1000 \mathrm{x} \mathrm{W}}$

V

Chlorophyll $b=22.9($ OD at 645) $-4.68($ OD at 663) x ----------

Ascorbic acid content (Ranganna, 1979) ${ }^{[8]}$.

$5 \mathrm{ml}$ of standard ascorbic acid solution was taken in a beaker and $5 \mathrm{ml}$ of HPO3 was added to it. This solution was titrated with the dye solution to a pink colour which persisted for 15 seconds. Dye factor ( $\mathrm{mg}$ of ascorbic acid per $\mathrm{ml}$ of the dye) was determined by using the formula:

Dye factor $=\frac{0.5}{-------}$
Here

0.5 means $0.5 \mathrm{mg}$ of ascorbic acid in $5 \mathrm{ml}$ of $100 \mathrm{ppm}$ standard ascorbic acid solution

Titre $=$ Volume of dye used to neutralize $5 \mathrm{ml}$ of $100 \mathrm{ppm}$ standard ascorbic acid solutions along with $5 \mathrm{ml}$ of metaphosphoric acid.

The ascorbic acid content was calculated by using the following formula

Titre $\mathrm{x}$ Dye Facter $\mathrm{x}$ volume made up

Ascorbic acid $(\mathrm{mg} / 100 \mathrm{~g})=$ Aliquot of extract x Weight of sample taken for estimation

\section{Here}

Titre $=$ Volume of dye used to titrate the aliquot of extract of a given sample.

\section{Results and Discussion}

The data regarding chlorophyll content of leaves as influenced by the gamma rays was found to be significant, the control treatment recorded maximum chlorophyll "a" (3.98 mg/g) and it was at par with the treatment $10 \mathrm{kR}, 20 \mathrm{kR}$ and $30 \mathrm{kR}$ of gamma rays, while the higher dose of gamma rays treatment $40 \mathrm{kR}$ of gamma rays recorded minimum chlorophyll "a" $(2.90 \mathrm{mg} / \mathrm{g})$. The lower dose of radiation treatment $10 \mathrm{kR}$ was recorded maximum chlorophyll "b" $(0.96 \mathrm{mg} / \mathrm{g})$ followed by the treatment $20 \mathrm{kR}$ of gamma rays, while the higher dose of radiation treatment $40 \mathrm{kR}$ recorded minimum chlorophyll " $\mathrm{b}$ " $(0.67 \mathrm{mg} / \mathrm{g})$. The treatment of $30 \mathrm{kR}$ gamma rays recorded maximum total chlorophyll $(1.14 \mathrm{mg} / \mathrm{g})$. The lower dose of radiation treatment $10 \mathrm{kR}$ gamma rays recorded minimum total chlorophyll $(0.78 \mathrm{mg} / \mathrm{g})$.

Plants with lower doses of mutagens shows protective response to the heat stress, which involves structural alternations in the photosynthetic apparatus as compared to higher doses. Prolonged irradiations damage to reaction centers is usually followed by chlorophyll loss.

Regarding ascorbic acid content, increasing doses of gamma radiation decreases in ascorbic acid as compared to control. The maximum ascorbic acid content (118.13 mg/100g) recorded in the control treatment followed by the lower dose of irradiated treatment $10 \mathrm{kR}(116.30 \mathrm{mg} / 100 \mathrm{~g})$. Whereas the higher dose of irradiated treatment $40 \mathrm{kR}$ gamma ray recorded minimum ascorbic acid content (111.93 mg/100g).

\section{Conclusion}

The present investigation indicated that, lower doses of gamma radiation have shows variability in the cv. Phule Jyoti for chlorophyll contents and ascorbic acid content. It needs to confirm the performance of mutants and their breeding behavior in subsequent generations.

\section{References}

1. Aruna S Desai, Srinath Rao. Effect of gamma radiation on germination and physiological aspects of Pigeon pea (Cajanus Cajan (L.) Millsp) seedlings. Int. J Res. App. Nat. Soc. Sci 2014;2(6):47-52.

2. Deepthi T, Dr. Remesh KN. Impact of EMS induction on morphological, anatomical and physiological traits of Bhindi Abelmoschus Esculentus (L.) Moench. Int. J Rec. Res. Life Sci 2016;3(2):4-11.

3. Hegazi AZ, Hamideldin N. The effect of gamma irradiation on enhancement of growth and seed yield of okra. J Hort. and Forestry 2010;2(3):038-051.

4. Mullainathan L, Sri Devi A. Effect of EMS and dES on oleoresin, capsanthin and ascorbic acid contents in chilli. Int. J Cur. Tr. Res 2012;1(3):110-114.

5. Naheed Akhtar. Effect of physical and chemical mutagens on morphological behavior of Tomato (Solanum Lycopersicum) cv. Rio Grande under heat stress conditions. Plant Breeding and Seed Science 2014;70:69-79.

6. Nusrat Saba, Bushra Mirza. Ethyl methane sulphonate induced genetic variability in Lycopersicon esculentum. Int. J Agri. Biol 2002;4(1):89-92. 
7. Nyla Jabeen, Bushra Mirza. Ethyl methane sulfonate enhances genetic variability in Capsicum annuum. Asian J Plant Sci 2002;1(4):425-428.

8. Ranganna S. Head Book of Analysis and Quality Control for Fruit and Vegetable Products. Tata McGraw-Hill 1979.

9. Sikder P, Biswas P, Hazra S, Akhtar A, Chattopadhyay AM, Badigannavar et al. Induction of mutation in tomato (Solanum lycopersicum L.) by gamma irradiation and EMS. Indian. J Genet 2013;73(4):392-399. 